\title{
O Escore de Jadad - Uma Luta Contra o Viés de Publicação
}

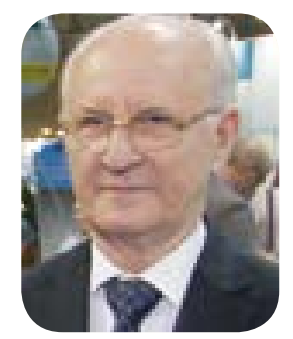

A publicação científica organizada se iniciou há 350 anos e apresentou nos últimos anos um crescimento exponencial.

Somente em língua inglesa existem 28.100 periódicos revistos por pares e que em seu conjunto publicam 2,5 milhões de artigos por ano. Sendo que 1,5 milhão na área de saúde e um terço desses em medicina.

Tal dimensão alcançada nos dá uma ideia da necessidade de uma sistematização da procura da informação assim fornecida num contexto que equaciona qualidade da informação com o tempo gasto para adquiri-la, entre outras coisas.

A revisão por pares nos oferece uma certa garantia da observação da qualidade do material publicado, porém, a rigor, está longe de ser absoluta.

A decisão de somente recorrer a periódicos de grande impacto de publicação é também uma forma avançada de uso efetivo do tempo de leitura, porém, mais uma vez, não nos confere garantia absoluta de ausência de vieses.

Além do mais, considere-se que, por vezes, faz-se necessária a leitura de publicações em jornais de menor impacto, por sua natureza exclusiva na área que seja o objeto do interesse momentâneo, em revisões sistemáticas ou por qualquer outro motivo que seja.

A maioria das evidências consolidadas em medicina, em terapêutica e também em diagnóstico, se baseia em estudos clínicos randomizados, que tentam, pelo processo de aleatorização, reduzir ao máximo possível o papel dos vieses nos resultados.

Reconhece, no entanto, a existência de vários outros possíveis vieses que não são de todo corrigidos pela randomização. Daí a necessidade de se contar com um instrumento de verificação da qualidade da publicação, existindo vários para tal finalidade.

Um desses, e de fácil aplicação, foi criado por um anestesista colombiano, Dr. Alejandro Jadad, em 1996, enquanto estagiava em Oxford, sendo o método reconhecido desde então como escore de Jadad ou método Oxford de verificação de qualidade da publicação.

\author{
Gilson Soares Feitosa ${ }^{1}$
}

Consiste de pontuações dadas a 3 perguntas: 1) Foi o estudo randomizado? 2) Houve mascaramento do processo investigativo? 3) Houve um esclarecimento sobre a disposição dos pacientes incluídos no ensaio? Conforme exposto na tabela abaixo:

Tabela 1. Escore de Jadad para estudos randomizados

\begin{tabular}{ll}
\hline \hline \multicolumn{1}{c}{ Perguntas } & \multicolumn{1}{c}{ Pontuação } \\
- Houve randomização? & 1- Sim \\
& 2- De boa qualidade \\
& -1- De má qualidade \\
\hline \hline - Houve mascaramento? & 1- Sim \\
& 2- De boa qualidade \\
& -1- De má qualidade \\
\hline \hline $\begin{array}{l}\text { - Houve detalhamento sobre } \\
\text { cacompanhamento de cada }\end{array}$ & 1- Sim \\
\hline \hline
\end{tabular}

Dessa forma, um trabalho poderá ter uma pontuação de 0 (zero) a 5, sendo considerados os de melhor qualidade aqueles com maior pontuação. $\mathrm{E}$, em algumas revisões sistemáticas, são excluídos aqueles com Jadad menor que 3.

Essa forma simples de julgar qualidade tem sido muito utilizada em revisões sistemáticas e tem muitos adeptos. Por outro lado há os que a criticam por julgarem-na muito simples.

De fato há escalas mais complexas, com listas de 25 perguntas mais exigentes, como a do CONSORT.

No entanto, dada a simplicidade do escore de Jadad ele continua sendo muito útil para uma rápida revisão de trabalhos numa área, ajudando a poupar o tempo do investigador ou daquele que seleciona artigos para seu próprio aprendizado em uma área.

Uma interessante observação com o uso do escore de Jadad, adveio da percepção de que os estudos publicados com resultados positivos tendem a ter um Jadad menor do que aqueles com resultado negativo, o que reflete, de saída, o viés de publicação que tende 
a rejeitar os estudos negativos, sendo muito mais exigentes para a sua aceitação.

\section{REFERÊNCIAS}

1- Plume, A., \& van Weijen, D. (2014, September). Publish or perish? The rise of the fractional author.... Research Trends, (38). Retrieved from www. researchtrends.com: http:// www.researchtrends.com/ issue-38-september-2014/publish-or-perish-the-rise-of-thefractional-author/

2- Jadad AR, Moore RA, Carroll D, et al. Assessing the quality of reports of randomized clinical trials: is blinding necessary? Control Clin Trials 1996;17:1-12

3- Altman DG, Schulz KF, Moher D, et al. The revised CONSORT statement for reporting randomized trials: explanation and elaboration. Ann Intern Med 2001;134:663-94.

1- Editor da Revista Científica do HSI

Endereço para correspondência:

gfeitosa@cardiol.br 